International Journal of Engineering \& Technology, $7(4.5)(2018) 435-438$
International Journal of Engineering \& Technology
SPC
Website: www.sciencepubco.com/index.php/IJET
Research paper

\title{
Synthesis, Characterization and Catalytic Activity of Nano-Iron (II) Schiff Base Complex in Suzuki-Miyaura Cross Coupling Reaction
}

\author{
Rasheeda M. Ansari and Badekai Ramachandra Bhat* \\ Catalysis and Materials Laboratory, Department of Chemistry, National Institute of Technology Karnataka, \\ Surathkal, Mangalore 575025, India. \\ *Corresponding author E-mail: ram@nitk.edu.in.
}

\begin{abstract}
A new nano-iron (II) Schiff base complex, $[\mathrm{Fe}(\mathrm{L})]$ where L is 1-((pyridin-2-ylimino)methyl)naphthalen-2-ol with octahedral geometry has been synthesized by the sonochemical (Ultrasonic irradiation) method. This method can promote the formation of nano-sized particles in short time with improved yield toward conventional method. The complex was characterized by FTIR, UV-Vis, TGA, SEM and elemental analysis. Particle size of synthesized complex was calculated from particle size analysis. Catalytic activity of the prepared complex was studied for Suzuki-Miyaura cross-coupling reaction. The synthesized complex showed great potential in catalytic activity with less concentration.
\end{abstract}

Keywords: Biphenyl; Iron Catalyst; Nano Complex; Schiff base; Suzuki-Miyaura coupling.

\section{Introduction}

Formation of $\mathrm{C}-\mathrm{C}$ bond by transition metal-catalyzed coupling reaction is understood to be a powerful tool for synthetic investigations. These complexes play a significant role in development of coordination chemistry in field of catalysis and enzymatic reactions, magnetism and molecular architectures, and liquid-crystal technology ${ }^{1-4}$. In addition, transition-metal nanoparticles for formation of carbon-carbon bonds are attractive to researchers ${ }^{5}$ Among, various catalytically active nanoparticles, palladium nanoparticles have gained considerable attention for the formation of C-C bonds ${ }^{6}$. Moreover, C-C coupling reaction (Suzuki and Heck) can be catalyzed by palladium nanostructures such as hollow spheres or nanoparticles of different emergence ${ }^{7}$. The application of transition-metal nanoparticles has been widely practiced for catalyzing the formation of carbon-carbon bond in the heterogeneous system since the last decade ${ }^{8}$. Nanoparticles have attained great interest in recent years as a result of their unique chemical and physical properties, which differ from their bulk materials, single atoms and can have potential applications in optoelectronics, catalysis, and ceramics etc ${ }^{9-11}$.

Since the past decade, various alternative approaches for C-C bond formation have been reported ${ }^{12}$. Transition-metals like nickel, cobalt, copper, iron etc. have also been utilized for the formation of $\mathrm{C}-\mathrm{C}$ bond ${ }^{13}$. Recently, $\mathrm{Fe}_{3} \mathrm{O}_{4}$ nanoparticles (NPs) have been investigated as efficient catalysts for $\mathrm{C}-\mathrm{C}$ bond formation ${ }^{14}$. Schiff bases are considered as a very important class of organic compounds which display wide applications in biological aspects. Transition metal complexes with Schiff base ligand possess rare catalytic activity with respect to cross-coupling reaction. Moreover, Schiff base ligands and their metal complexes have been widely researched ${ }^{15}$. However, the functional applications of Schiff bases and their metal complexes greatly rely on several properties, such as complexation ability towards metals ${ }^{16}$, antibacterial activity ${ }^{17}$, anti-cancer activity, fungicidal ${ }^{18}$ etc. On the other hand, the particle size plays important role on catalysis, so the synthesis of nano-sized compound has a basal role in many fields. In addition, the coupling of aryl halides with phenylboronic acids under mild condition is a subject of immense interest for both academicians and researchers. In the present work, we have described the synthesis of new nano-iron (II) Schiff base complex of a Schiff base ligand, namely 1-((pyridin-2ylimino)methyl)naphthalen-2-ol using sonochemical methods. Nano-iron (II) Schiff base complex was characterized and its catalytic activity was investigated for Suzuki cross coupling reaction.

\section{Materials and Method}

All chemicals used were of analytical reagent (AR) grade and used without any further purification. 2-aminopyridine, 2-hydroxy-1naphthaldehyde were procured from Merck India. Ferrous chloride (hydrated) was procured from loba chemie. Acetonitrile (ACN), 1,4-dioxane, toluene, ethyl alcohol, methyl alcohol, diethyl ether, tetrahydrofuran (THF), dimethylformamide (DMF), potassium tertiary butoxide, cesium carbonate, potassium carbonate, sodium carbonate and triethylamine used in the study were purchased from Sigma-Aldrich.

${ }^{1} \mathrm{H}-\mathrm{NMR}$ spectra were recorded in Bruker AV 400 instrument using TMS as an internal standard. The spectra of the ligand and complex were recorded in DMSO. FTIR spectra were recorded on a Bruker-Alpha FTIR spectrophotometer as $\mathrm{KBr}$ pellet in the frequency range 400-4000 $\mathrm{cm}^{-1}$. Electronic spectra of ligand and complex were measured on Analytik Jena SPECORD S600 UVVis spectrophotometer in the $200-600 \mathrm{~nm}$ range. Thermogravimetric measurements were performed on (EXSTAR-6000) using nitrogen as the carrier gas (flow rate: $50 \mathrm{~mL} / \mathrm{min}$ ) with heating rate 
$10{ }^{\circ} \mathrm{C} / \mathrm{min}$. The $\mathrm{C}, \mathrm{H}$ and $\mathrm{N}$ contents of the ligand and metal complex was determined using microanalysis Thermoflash EA1112 series elemental analyzer. The magnetic susceptibilities of the complex was recorded at room temperature on a Sherwood UK magnetic balance, $\mathrm{Hg}\left[\mathrm{Co}(\mathrm{SCN})_{4}\right]$ was used as a calibrant. SEM analysis was carried out by JEOL-JSM-6360LV model to investigate the morphology of the specimen. Particle size measurement was carried out on Horiba particle size analyzer. The cross coupling product was analyzed using Gas Chromatography (GC) (Shimadzu 2014, Japan), siloxane Restek capillary column (30 m length and $0.25 \mathrm{~mm}$ diameter) and Flame Ionization Detector. The initial column temperature was increased from $60{ }^{\circ} \mathrm{C}$ to $150{ }^{\circ} \mathrm{C}$ at the rate of $10{ }^{\circ} \mathrm{C} / \mathrm{min}$ and then to $220{ }^{\circ} \mathrm{C}$ at the rate of $40{ }^{\circ} \mathrm{C} / \mathrm{min}$. Nitrogen gas was used as the carrier gas.

2-aminopyridine (0. $095 \mathrm{~g}, 1 \mathrm{mmol})$ and 2-hydroxy-1naphthaldehyde $(0.172 \mathrm{~g}, 1 \mathrm{mmol})$ were dissolved in ethanol and heated to $60{ }^{\circ} \mathrm{C}$ in a $50 \mathrm{~mL}$ round bottom flask. The reaction mixture was then refluxed for 3 hours and filtered. The obtained product then washed with diethyl ether and re-crystallized from ethanol and dried. Chemical Formula: $\mathrm{C}_{16} \mathrm{H}_{12} \mathrm{~N}_{2} \mathrm{O}$; Melting point: 180 ${ }^{\circ} \mathrm{C}$; Yield: 80\%; Color: Mehendi Yellow. Elemental Anal: Found (\%): C-77.45, H-4.75, N-11.00; Calc. (\%): C-77.40, H-4.80, N11.28; FTIR (KBr) $\mathrm{cm}^{-1}: 1618.59(\mathrm{vC}=\mathrm{N}), 1137.91$ ( $\left.\mathrm{vC}-\mathrm{O}\right)$, 3495.46 ( $\mathrm{vO}-\mathrm{H})$.

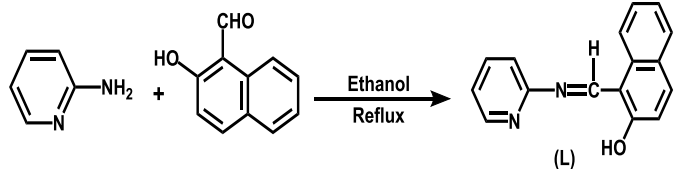

Scheme 1: Synthesis of ligand (L)

A proper volume of ligand $(0.496 \mathrm{gm}, 2.0 \mathrm{mmol})$ solution in (ethanol) $(5 \mathrm{~mL})$ was added in dropwise manner under the ultrasonic irradiation to the prepared $\mathrm{FeCl}_{2} \cdot \mathrm{XH}_{2} \mathrm{O}(0.127 \mathrm{gm}, 1.0 \mathrm{mmol})$ solution $(5 \mathrm{~mL})$ in ethanol. The mixture was irradiated under ultrasonic waves for one hour. The obtained solid was filtered, subsequently washed with cold methanol and dried. Chemical Formula: $\mathrm{C}_{32} \mathrm{H}_{22} \mathrm{FeN}_{4} \mathrm{O}_{2}$; Yield: $80 \%$; Color: Dark brown. Elemental Anal: Found (\%): C-77.45, H-4.78, N-9.72; Calc. (\%): C-70.35, $\mathrm{H}-4.86, \mathrm{~N}-9.65$; FTIR $(\mathrm{KBr}) \mathrm{cm}^{-1}: 1561.73(\mathrm{vC}=\mathrm{N}), 1124.21$ (vCO), 3448.14 (vO-H), $496.24(\mathrm{vFe}-\mathrm{N}), 421.98$ (vFe-O).

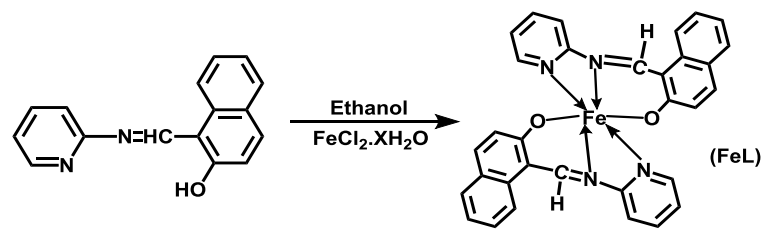

Scheme 2: Synthesis of Complex (FeL)

Aryl halide (1.0 mmol), phenylboronic acid $(1.5 \mathrm{mmol}), \mathrm{K}_{2} \mathrm{CO}_{3}$ $(2.0 \mathrm{mmol})$, catalyst $(0.04 \mathrm{mmol})$ and 1,4 -dioxane $(2 \mathrm{~mL})$ were added to a $5 \mathrm{~mL}$ flask, and the mixture was stirred in parallel synthesizer for 8 hours at $110{ }^{\circ} \mathrm{C}$. The progresses of the reactions were monitored by Gas chromatography. The internal standard was used and calibrated against each and every one of the crosscoupling products.

\section{Results and Discussion}

The ${ }^{1} \mathrm{H}$ NMR spectrum of the ligand was recorded in DMSO solvent to confirm the number of proton present in the molecule. The -OH peak was observed around $15.21 \mathrm{ppm}$. The peak at $9.58 \mathrm{ppm}$ was observed for azomethine proton (Fig. 1).

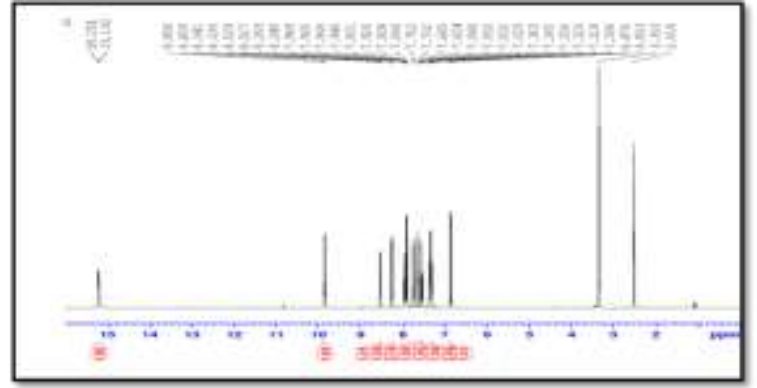

Fig. 1: ${ }^{1} \mathrm{H}$ NMR of Ligand

FTIR spectra of ligand and the complex are shown in the Figure 2. The strong band in ligand at $1618.59 \mathrm{~cm}^{-1}$ assignable to azomethine $v(C=N)$ group and and $\mathrm{O}-\mathrm{H}$ peak appears at $3495.46 \mathrm{~cm}^{-1}$. The peak in the region $1137.91 \mathrm{~cm}^{-1}$ is indicative of phenolic $v(\mathrm{C}$ O) stretching. Moreover, for complex, the appearance of a band for $v(\mathrm{CH}=\mathrm{N})$ in the range of $1561.73 \mathrm{~cm}^{-1}$ indicates a shifting to the lower wave numbers compared to ligand indicating the complexion of ligand with metal atom through nitrogen atom has been formed. Phenolic $v(\mathrm{C}-\mathrm{O})$ stretching in complex is shifted from $1137.91 \mathrm{~cm}^{-1}$ to $1124.21 \mathrm{~cm}^{-1}$ indicating coordination of the phenolic oxygen of ligand to the metal ion. The new band at 421.98 $\mathrm{cm}^{-1}$ in complex, tentatively assign coordination of metal with oxygen atom $v(\mathrm{Fe}-\mathrm{O})$. The band which appear around $496.24 \mathrm{~cm}^{-1}$ in the spectrum of complex may be assigned to the coordination of metal with a nitrogen atom $(\mathrm{Fe}-\mathrm{N})^{19}$.

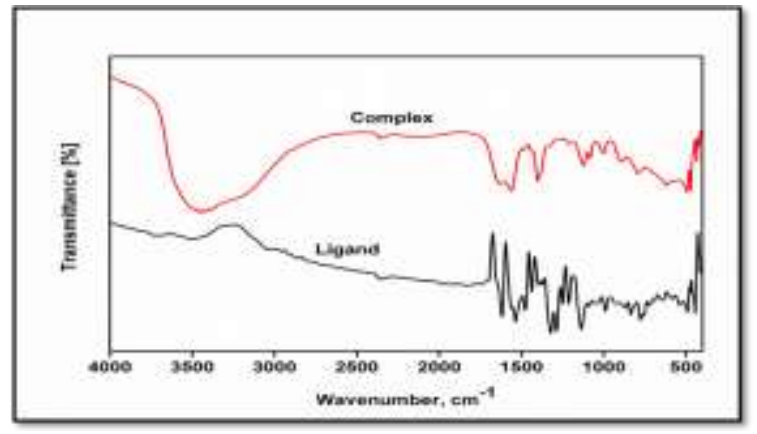

Fig. 2: FTIR spectrum of ligand and complex

The electronic spectra of synthesized ligand and complex were recorded in methanol solvent (Fig. 3). The ligand shows peaks at $228 \mathrm{~nm}, 282 \mathrm{~nm}$ and $332 \mathrm{~nm}$ which are due to $\pi-\pi^{*}, \mathrm{n}-\pi^{*}$ transitions. In case of synthesized complex, peaks at $245 \mathrm{~nm}, 299 \mathrm{~nm}$, $345 \mathrm{~nm}$ were observed. The absorption bands which we observed in the free ligand spectrum have been shifted to lower energy region in the spectra of complex because of the ligand coordination with a metal ion. These transitions are due to intra-ligand charge transfer transitions (ILCT) and ligand to metal charge transfer transitions (LMCT). Moreover, in case of complex, peaks at 420 $\mathrm{nm}$ and $438 \mathrm{~nm}$ were observed (d-d transition) ${ }^{20}$.

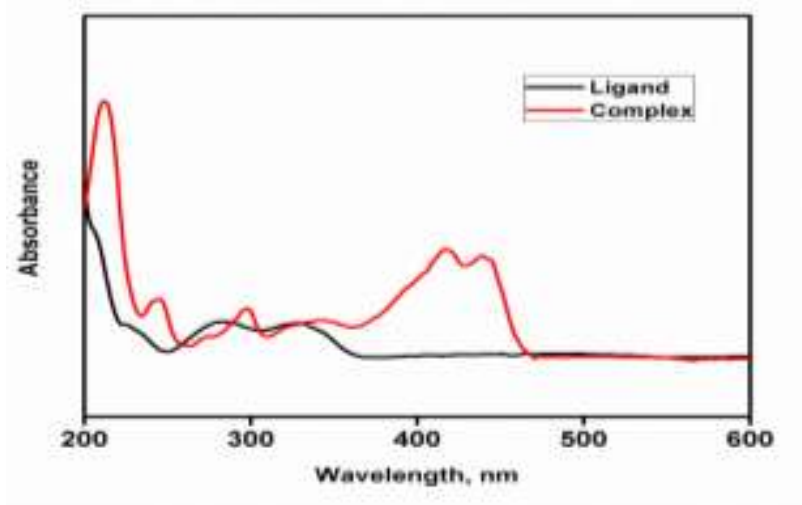

Fig. 3: UV-Vis spectrum of ligand and complex 
The magnetic properties of the complex at room temperature have been investigated. The magnetic moment of complex was found 4.10 BM, which indicates that 4 unpaired electron is present in the complex. The paramagnetic nature revealed octahedral geometry of the synthesized complex.

The size of the nano-Fe particles was observed $47.5 \mathrm{~nm}$ (Fig. 4). The morphology and particle size of the nano-iron (II) complex catalyst was studied by SEM images (Fig. 5). As can be seen, the nano-Fe particles tubular nanostructure of the nanotubes (Fig. 5). The thermal behavior of the Schiff base ligand and its metal complex was studied by using thermogravimetric techniques in the range of $30-600{ }^{\circ} \mathrm{C}$ in a nitrogen atmosphere. The TGA curve of ligand and metal complex are given in Fig. 6. The purpose of the thermal study is to confirm the course of the degradation and the presence of the hydrated water molecules in the complex. In Figure 6 , as can be seen, decomposition of the complex was completed in a single step. The remaining percentage mass loss can be assigned for iron oxide residue. The absence of the peak around $200{ }^{\circ} \mathrm{C}$ confirms that no water molecule present in the complex.

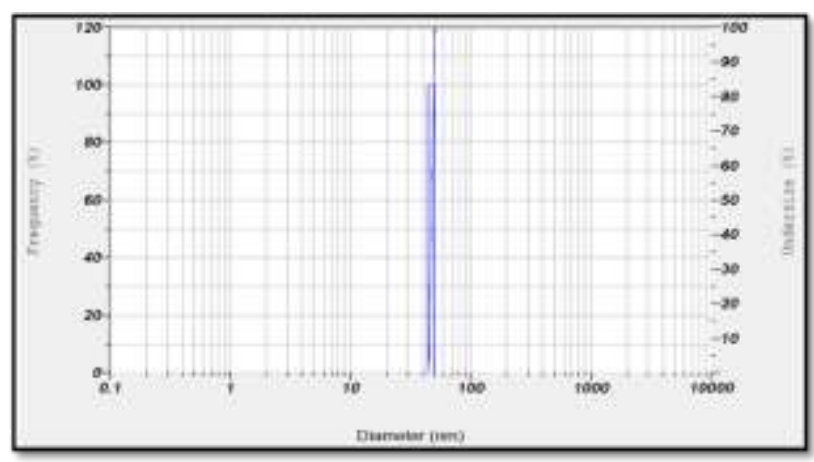

Fig. 4: Particle size distribution of the synthesized complex

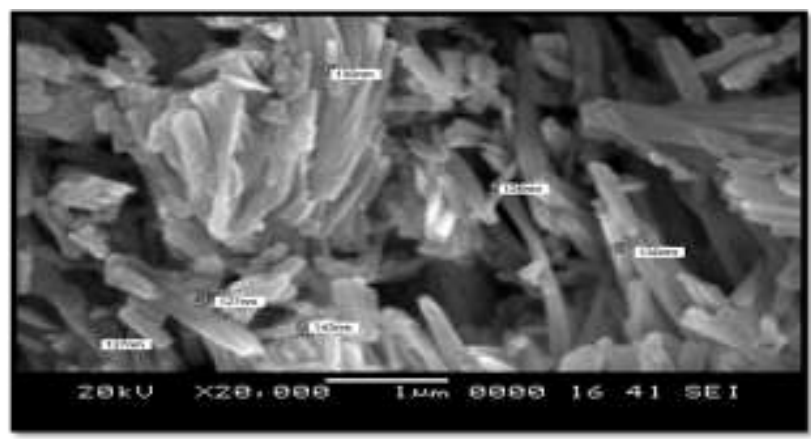

Fig. 5: SEM micrographs of the complex

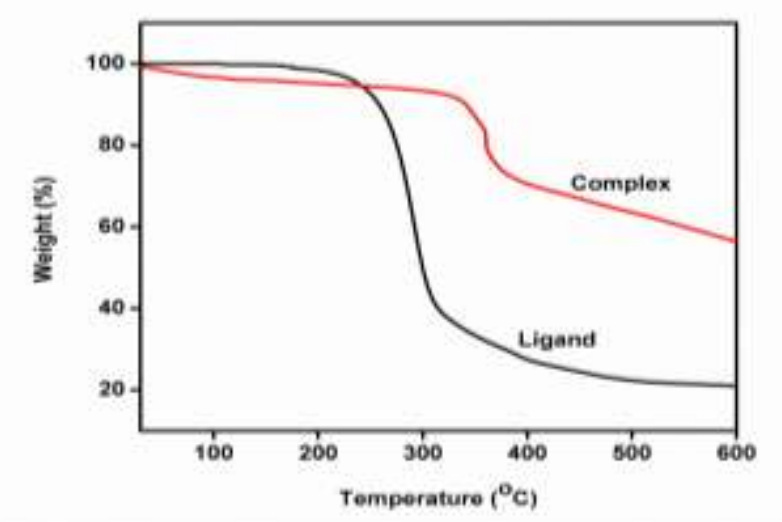

Fig. 6: TGA of ligand and complex

We employed the coupling of 4-bromobenzonitrile and phenylboronic acid as the model reaction to study the suzuki reaction using the nano-iron (II) Schiff base complex as a catalyst. The effects of the base, solvent, time and concentration of the catalyst on the Suzuki coupling of bromobenzonitrile and phenylboronic acid were investigated. The basic environment is essential for the Suzuki reaction. Among the bases examined (Table 1, entries 1-5), $\mathrm{K}_{2} \mathrm{CO}_{3}$ showed the best effect. The impact of solvents on the reaction was also investigated (Table 2, entries 1-5) and 1,4-dioxane gave the best result. Product yield dependence on the reaction time was investigated by analyzing the reaction mixture at regular intervals of time. Product conversion was observed to increase with reaction time till the completion of 8 hours. The conversion remained almost insignificant after 8 hours (Fig. 7). Hence, optimized reaction time for coupling reaction was fixed at 8 hours. Product yield dependence on the concentration of catalyst was investigated by analyzing the reaction mixture with different catalyst concentration from $0.01 \mathrm{mmol}$ to $0.05 \mathrm{mmol}$ (Table 3). The conversion result showed almost constant yield with 0.04 and 0.05 mmol catalyst concentrations. Hence, $0.04 \mathrm{mmol}$ concentration was taken for the further catalytic studies.

Table 1: Effect of base on Suzuki coupling

\begin{tabular}{|r|c|c|c|}
\hline Entry & Bases & Solvent & Yield $^{\mathbf{a}}$ \\
\hline 1 & $\mathrm{Et}_{3} \mathrm{~N}$ & & 72 \\
\hline 2 & $\mathrm{~K}_{2} \mathrm{CO}_{3}$ & & 78 \\
\hline 3 & $\mathrm{Cs}_{2} \mathrm{CO}_{3}$ & & 74 \\
\hline 4 & $\mathrm{Na}_{2} \mathrm{CO}_{3}$ & \multirow{2}{*}{$1,4-$ dioxane } & 68 \\
\hline 5 & $\mathrm{KOtBu}$ & & 61 \\
\hline
\end{tabular}

Table 2: Effect of solvents

\begin{tabular}{|r|c|c|c|}
\hline Entry & Solvents & Base & Yield $^{\mathbf{a}}$ \\
\hline 1 & Acetonitrile & & 70 \\
\hline 2 & 1,4-dioxane & & 78 \\
\hline 3 & Toluene & \multirow{2}{*}{$\mathrm{K}_{2} \mathrm{CO}_{3}$} & 75 \\
& THF & & 60 \\
\hline 4 & DMF & & 64 \\
\hline 5 & & & \\
& & &
\end{tabular}

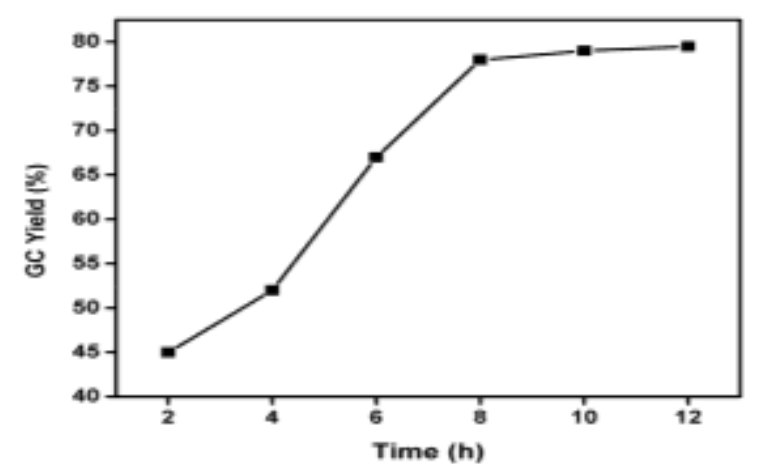

Fig. 7: Effect of reaction time

Table 3: Effect of catalyst concentration

\begin{tabular}{|c|c|c|c|c|}
\hline Entry & $\begin{array}{l}\text { Concentration of } \\
\text { catalyst }\end{array}$ & Bases & Solvent & Yield $^{\mathrm{a}}$ \\
\hline 1 & 0.01 & \multirow{5}{*}{$\mathrm{K}_{2} \mathrm{CO}_{3}$} & \multirow{5}{*}{$\begin{array}{l}1,4- \\
\text { dioxane }\end{array}$} & 51 \\
\hline 2 & 0.02 & & & 59 \\
\hline 3 & 0.03 & & & 68 \\
\hline 4 & 0.04 & & & 78 \\
\hline 5 & 0.05 & & & 78.50 \\
\hline
\end{tabular}

Further, different substituted aryl halides were used to extend the cross-coupling reaction with phenylboronic acid using the optimized reaction conditions. The results of different substituent are summarized in Table 4. The catalyst was found to catalyze the coupling reactions effectively. The conversion pattern with different substituents on the aryl halides was different.

Table 4: Catalytic activity study for complex

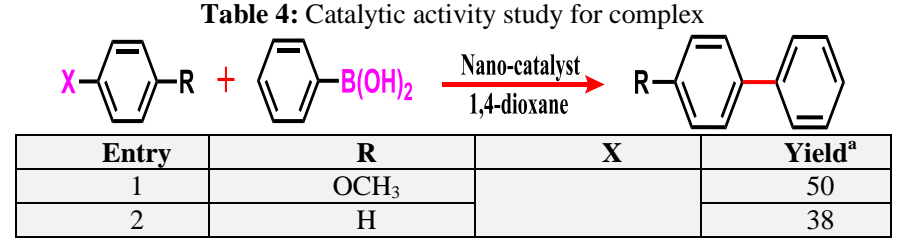




\begin{tabular}{|c|c|c|c|}
\hline 3 & $\mathrm{CN}$ & \multirow{6}{*}{$\mathrm{Br}$} & 78 \\
\hline 4 & $\mathrm{COCH}_{3}$ & & 79 \\
\hline 5 & $\mathrm{NHCOCH}_{3}$ & & 67 \\
\hline 6 & $\mathrm{OH}$ & & 50 \\
\hline 7 & $\mathrm{CH}_{3}$ & & 46 \\
\hline 8 & $\mathrm{~F}$ & & 57 \\
\hline 9 & $\mathrm{OH}$ & \multirow[b]{2}{*}{ I } & 58 \\
\hline 10 & $\mathrm{CN}$ & & 80 \\
\hline
\end{tabular}

Reaction conditions: Aryl halide $(1.0 \mathrm{mmol})$, phenylboronic acid $(1.5$ $\mathrm{mmol}), \mathrm{K}_{2} \mathrm{CO}_{3}(2.0 \mathrm{mmol})$, catalyst $(0.04 \mathrm{mmol})$, solvent $(2.0 \mathrm{~mL}), 8 \mathrm{~h}$. ${ }^{a}$ Yield determined by GC.

\section{Conclusion}

A new octahedral tubular nano-iron (II) Schiff base complex, $[\mathrm{Fe}(\mathrm{L})]$ where L [1-((pyridin-2-ylimino)methyl)naphthalen-2-ol] has been synthesized via Ultrasonic irradiation and characterized. Suzuki cross-coupling of different aryl halides and phenylboronic acids was catalyzed with synthesized nano-iron complex. The synthesized complex showed great potential in catalytic activity. Better result was found in 1,4-dioxane solvent with $\mathrm{K}_{2} \mathrm{CO}_{3}$ as a base using a catalyst load of $0.04 \mathrm{mmol}$ with a reaction time of 8 hours. The yields varied on the basis of substrates having either electron-donating groups or electron-withdrawing groups. Among the halides, iodide was observed to be a better leaving group. It was concluded that the catalytic activity of the nano-iron (II) Schiff base complex could be exploited for the carbon-carbon cross coupling reaction efficiently.

\section{Acknowledgement}

The authors would like to acknowledge National Institute of Technology Karnataka for extending the research fellowship.

\section{References}

[1] H.B. Kagan, Asymmetric catalytic reduction with transition metal complexes. I. Catalytic system of rhodium (I) with (-)-2, 3-0isopropylidene-2, 3-dihydroxy-1, 4-bis (diphenylphosphino) butane, a new chiral diphosphine, Journal of the American Chemical Society, 94 (1972) 6429-6433.

[2] P.E. Siegbahn, The performance of hybrid DFT for mechanisms involving transition metal complexes in enzymes, Journal of Biological Inorganic Chemistry, 11 (2006) 695-701.

[3] A.P. Gingsberg, Magnetic exchange in transition metal complexes vi: Aspects of exchange coupling in magnetic cluster complexes, Inorganica Chimica Acta Reviews, 5 (1971) 45-68.

[4] K. Ohta, H. Muroki, A. Takagi, K.-I. Hatada, H. Ema, I. Yamamoto, K. Matsuzaki, Discotic liquid crystals of transition metal complexes, 3: the first-established discotic lamellar phase in bis [1, 3-di (pnalkoxyphenyl) propane-1, 3-dionato] copper (II), Molecular Crystals and Liquid Crystals, 140 (1986) 131-152.

[5] M. Moreno-Manas, R. Pleixats, Formation of carbon- carbon bonds under catalysis by transition-metal nanoparticles, Accounts of Chemical Research, 36 (2003) 638-643.

[6] Z. Dehbanipour, M. Moghadam, S. Tangestaninejad, V. Mirkhani, I. Mohammadpoor-Baltork, Nano-silica supported palladium catalyst: Synthesis, characterization and application of its activity in Sonogashira cross-coupling reactions, Journal of Organometallic Chemistry, 853 (2017) 5-12.

[7] S.-W. Kim, M. Kim, W.Y. Lee, T. Hyeon, Fabrication of hollow palladium spheres and their successful application to the recyclable heterogeneous catalyst for Suzuki coupling reactions, Journal of the American Chemical Society, 124 (2002) 7642-7643.

[8] B. Tamami, S. Ghasemi, Palladium nanoparticles supported on modified crosslinked polyacrylamide containing phosphinite ligand: A novel and efficient heterogeneous catalyst for carboncarbon cross-coupling reactions, Journal of Molecular Catalysis A Chemical, 322 (2010) 98-105. doi:10.1016/j.molcata.2010.02.025.
[9] T. Teranishi, I. Kiyokawa, M. Miyake, Synthesis of monodisperse gold nanoparticles using linear polymers as protective agents, Advanced Materials, 10 (1998) 596-599.

[10] B.F. Johnson, Nanoparticles in catalysis, Topics in Catalysis, 24 (2003) 147-159.

[11] K. Zhang, A.K. Pradhan, G.B. Loutts, U.N. Roy, Y. Cui, A. Burger, Enhanced luminescence and size effects of $\mathrm{Y} 2 \mathrm{O}$ 3: Eu 3+ nanoparticles and ceramics revealed by $\mathrm{x}$ rays and Raman scattering, Journal of the Optical Society of America B, 21 (2004) 1804-1808.

[12] S.H. Cho, J.Y. Kim, J. Kwak, S. Chang, Recent advances in the transition metal-catalyzed twofold oxidative $\mathrm{C}-\mathrm{H}$ bond activation strategy for $\mathrm{C}-\mathrm{C}$ and $\mathrm{C}-\mathrm{N}$ bond formation, Chemical Society Review, 40 (2011) 5068-5083.

[13] E. Nakamura, N. Yoshikai, Low-Valent Iron-Catalyzed C- C Bond Formation- Addition, Substitution, and $\mathrm{C}-\mathrm{H}$ Bond Activation, Journal of Organic Chemistry, 75 (2010) 6061-6067.

[14] H. Firouzabadi, N. Iranpoor, M. Gholinejad, J. Hoseini, Magnetite (Fe3O4) Nanoparticles-Catalyzed Sonogashira-Hagihara Reactions in Ethylene Glycol under Ligand-Free Conditions, Advance Synthesis \& Catalysis, 353 (2011) 125-132.

[15] S. Layek, Anuradha, B. Agrahari, D.D. Pathak, Synthesis and characterization of a new Pd(II)-Schiff base complex [Pd(APD)2]: An efficient and recyclable catalyst for Heck-Mizoroki and SuzukiMiyaura reactions, Journal of Organometallic Chemistry, 846 (2017) 105-112. doi:10.1016/j.jorganchem.2017.05.049.

[16] R.M. Ansari, B.R. Bhat, Schiff base transition metal complexes for Suzuki-Miyaura cross-coupling reaction, Journal of Chemical Sciences, 129 (2017) 1483-1490. doi:10.1007/s12039-017-1347-6.

[17] N. Raman, A. Kulandaisamy, A. Shunmugasundaram, K. Jeyasubramanian, Synthesis, spectral, redox and antimicrobial activities of Schiff base complexes derived from 1-phenyl-2, 3-dimethyl-4aminopyrazol-5-one and acetoacetanilide, Transition Metal Chemistry, 26 (2001) 131-135.

[18] S. Jone Kirubavathy, S. Chitra, Structural, theoretical investigations and biological evaluation of $\mathrm{Cu}(\mathrm{II}), \mathrm{Ni}$ (II) and $\mathrm{Co}(\mathrm{II})$ complexes of mercapto-pyrimidine schiff bases, Journal of Molecular Structure, 1147 (2017) 797-809. doi:10.1016/j.molstruc.2017.07.019.

[19] K. Yunus, H. Mutlu, İ. Gazi, Uv-Vis Spectra and Fluorescence Properties of Two Iminooxime Ligands and Their Metal Complexes: Optical Band Gaps, Gazi University Journal of Science, 23 (2010) 13-18.

[20] S.A. Carabineiro, L.C. Silva, P.T. Gomes, L.C. Pereira, L.F. Veiros, S.I. Pascu, M.T. Duarte, S. Namorado, R.T. Henriques, Synthesis and characterization of tetrahedral and square planar bis (iminopyrrolyl) complexes of cobalt (II), Inorganic Chemistry, 46 (2007) 6880-6890. 